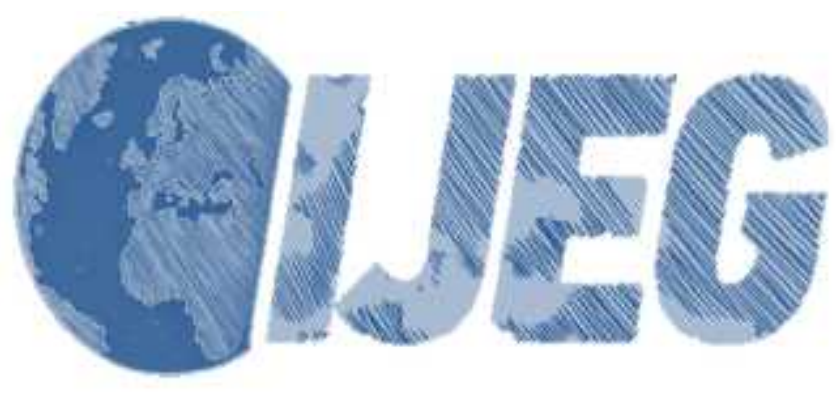

International Journal of Engineering and Geosciences (IJEG), Vol; 1 , Issue; 01, pp. 24-33, October, 2016, ISSN 2548-0960, Turkey, DOI: Your DOI number

\title{
VARIABILITY AND DECADAL EVOLUTION OF TEMPERATURE AND SALINITY IN THE MEDITERRANEAN SEA SURFACE
}

\author{
Nacef, L., ${ }^{1 *}$ Bachari, N.E.I., ${ }^{1}$ Bouda, A., ${ }^{2}$ and Boubnia, R., ${ }^{2}$ \\ ${ }^{1}$ Selçuk University, Engineering Faculty, Department of Geomatic Engineering, Konya, Turkey \\ (yakar/etusat/orhanosman@ @elcuk.edu.tr); \\ ${ }^{1}$ Department of Ecology and Environment, Faculty of Biological Sciences, Houari Boumediene University of Science \\ and Technology (USTHB), B.P 32 El-Alia 16111, Algiers, Algeria. (nacef_l, bachari10@yahoo.fr); \\ ${ }^{2}$ École Nationale Supérieure des Sciences de la Mer et de l'Aménagement du Littoral (ENSSMAL), Campus \\ universitaire de Delly Ibrahim, Bois des Cars, B.P. 19, 16320, Algiers, Algeria. (abderbouda, rboubnia@ yahoo.fr)
}

*Corresponding Author, Received: 08/06/2016, Accepted: 20/07/2016

\begin{abstract}
Based on the Med-Atlas 20002 database data at Mediterranean Sea surface, analysis of spatial and temporal variations of temperature and salinity, as well as, the search of its possible trends are the main goals of this work. The used statistical techniques allowed us to obtain various climatological fields of temperature and salinity, on a period of 45 years (1955-1999). Spatial and temporal analysis of those fields shows that the north-south gradient is weaker than the east-west gradient. The strongest variability in both mean fields is sharper in downwelling areas than anywhere else, showing the colder and less saline surface waters. Warmer and saltiest water surface are located in southeast of the Levantine basin. The eastern Mediterranean Sea is generally more saline than the western basin. The temperature seasonal cycle is more marked than the salinity seasonal cycle. The summer-winter thermal and saline fields are completely contrasted, especially in the northern Adriatic Sea. The largest positive peak of inter-annual temperature variability is encountered in 1994, the largest negative peak in 1992. Whereas those related to salinity observed in 1983 and in 1997 respectively. The decadal variations indicate a cooling of Mediterranean Sea surface in 1970s and a northward warming since 1980s that accelerated in 1990s. The eastern Mediterranean Sea exhibits a higher warming rate as compared to the western basin, but the average increase is about $0.2{ }^{\circ} \mathrm{C} /$ decade. The Salinity rising corresponds to the cooling periods and the decreasing is associated with the warming ones.
\end{abstract}

Keywords: Mediterranean Sea surface, Temperature, Salinity, Spatio-temporal/Interannual/decadal variability. 


\section{INTRODUCTION}

The climate of the earth is extremely complex due to interactions between the atmosphere, hydrosphere, geosphere, biosphere and cryosphere. Moreover, the exchange of energy, of matter and moisture between these environmental spheres are the main mechanisms that govern the climate system (Simmons \& Bengtsson, 1984; Beniston, 2004; IPCC, 2007).

The global atmospheric and oceanic circulations are strongly interdependent and the Sea Surface Temperature (SST) is the link between the two (Gill, 1982). Among others, ocean circulation depends on characteristics of the different water masses. A water mass acquires its basic characteristics that are the SST and the Sea Surface Salinity (SSS) under the effect of exchanges with the atmosphere. The thermohaline circulation assigned particularly by surface salinity that will determine the threshold in temperature beneath which surface water will plunge. In the same way as temperature and pressure, salinity modulates the distribution of heat in the oceans and affects the density of seawater that is a fundamental parameter ocean circulation (Pickard \& Emery, 1964). Changes in temperature and salinity can reduce the deep-water masses formation, affecting the duration, frequency and intensity of this process. This could ultimately have an impact on biodiversity, due to the local climate change (Pusceddu et al., 2010).

The Mediterranean Sea behaves as a downscaled ocean where the main processes that affect the global ocean are present (Béthoux et al., 1999; CIESM, 2002; Lejeusne et al., 2010). Considered as a thermodynamic machine that exchange water with Atlantic Ocean through the Gibraltar Strait and heat with atmosphere through its surface. Mediterranean basin shows an excess of evaporation over the freshwater input and heat loss through the ocean-atmosphere interactions. These losses of fresh water and heat are compensated by two exchange layers in the Strait of Gibraltar: a top layer, towards the Mediterranean including a relatively warm and fresh water inflow and underlying relatively colder and saltier layer towards the Atlantic (Bryden et al., 1994; Tsimplis \& Bryden, 2000).

Mediterranean Sea circulation is determined by heat exchanges, through the SST and freshwater, that depend on weather conditions and ocean characteristics (Tsimplis et al., 2005). The water flux and SST are crucial in dense water formation, and thus in the Mediterranean thermohaline circulation (Béthoux et al., 1999; Barnier et al., 2006). Consequently, they affect the characteristics of Mediterranean water masses (temperature, salinity and density) and can potentially affect the Atlantic Ocean circulation by changing the Mediterranean outgoing waters properties (Potter \& Lozier, 2004; Tsimplis et al., 2005; Millot et al., 2006). SST in the Mediterranean can also influence the atmosphere properties at lower levels and occurrence of episodes of heavy coastal rainfall (Castellari et al., 1998; Li, 2006; Lebeaupin et al., 2006). In the Mediterranean, oceanographic and physical aspects of climate change are described in many reports and scientific studies, but there are still uncertainties about the extent of physical and chemical expected changes at regional and local scales (Lionello, 2012).

Despite a great progress in measuring and understanding data errors, the performed SST and SSS climatologies from different data sets in the Mediterranean show a wide range of discrepancies that we are still struggling to reduce them (Hewitt \& Griggs, 2004; Sanchez Gomez et al., 2008, 2009). To overcome some of these gaps, the SST and SSS variability is an efficient tool that can define the accuracy requirements, determine the sampling conditions and the precision with which the parameter can be determined. Thus, improving our knowledge of Mediterranean water masses characteristics, particularly the surface temperature and salinity, and their variability is a daunting challenge for the scientific community in the field of measurements and modelling in Mediterranean region. Obtain accurate estimates of these parameters is important for understanding the circulation and Mediterranean climate as well as their evolution in the context of climate change. Furthermore, systematic assessments of variability of basic hydrological parameters (temperature and salinity) in relation to climate and to changes in biogeochemical processes and biodiversity are crucial to understand the mode of response/functioning of the marine ecosystem.

In this study, we took advantage of the MEDAR/MEDATLAS 2002 database release to build different climatologies of temperature and salinity at various spatial and temporal scales. Use these climatologies to assess the spatio-temporal variability and to infer the decadal change in the fields of temperature and salinity at Mediterranean Sea surface. We focus our effort on study of variations and decadal trends. We will be expecting that this quantitative description improves measurement accuracy and increases our understanding of the Mediterranean processes.

\section{MATERIAL AND METHODS}

\subsection{Data description}

Data from 1889 to 2000 of temperature and salinity profiles, contained in MEDAR/MEDATLAS (Fichaut et al., 2003; Medar group, 2002), are the main source of data in this study. On the 1900-2000 period, we chose to extract only data collected with bottles and Conductivity-Temperature-Depth "CTD", data collected with Mechanical-Bathy-Thermographs "MBT" and eXpendable Bathy-Thermographs "XBT" are inherently less accurate. The quality control procedures of the data already made by the MEDAR/MEDATLAS group allow us to extract the data at Mediterranean Sea surface level that have successfully passed the tests.

On the investigated period, temporal and spatial distribution of extracted data shows that the largest number of data refers to the 1946-2000 period. Density of observations is weaker in winter months. The highest density cover the gulf of Lyons, the Ligurian Sea, the North Adriatic Sea and the Alboran Sea. Southern Levantine basin and the coasts of Tunisia and Libya suffer from a severe lack of data. This heterogeneity is the result of weather conditions and the tendency to make more investigations for specific processes (e.g., in the Gulf of Lions for tracking the deep waters formation). Several Mediterranean areas, mainly its southern parts, are widely under-sampled due to historical-political difficulties, as well as to financial and logistic constraints. This is a serious limit which makes the interpretation of data more difficult (Millot \& Briand, 2002) and prevents reliable trend detection (Millot \& Taupier-Letage, 2005).

\subsection{Data processing}

For achieving different climatologies at various spatial and temporal scales, we needed to construct complete data series where data availability is the first limitation one can expect. Therefore, the data processing aims at interpolating the available information on the required time and space scales. 
Here, we describe the main steps in our approach. As a first step, we adopted the 29 boxes defined by MEDAR/MEDATLAS 2002. The choice of this zonation is supported by the use of such areas in the quality control and regional parameterization of MEDATLAS data. These areas represent the spatial grid with which one can filter the most details of ocean circulation characteristics and properties of the Mediterranean surface. We applied a variance-based analysis to the temperature and salinity data from these 29 boxes. This analysis helps to aggregate the dependant areas. The results of this analysis allowed us to identify 18 independent zones (Fig. 1). This grid is used for subsequent binning of the data and in remaining processing and analysis. Data for each variable are then averaged monthly for all 18 zones for the period running from January 1955 to December 1999. We note that before 1955 and during 2000, the data are too scarce to be interpolated.

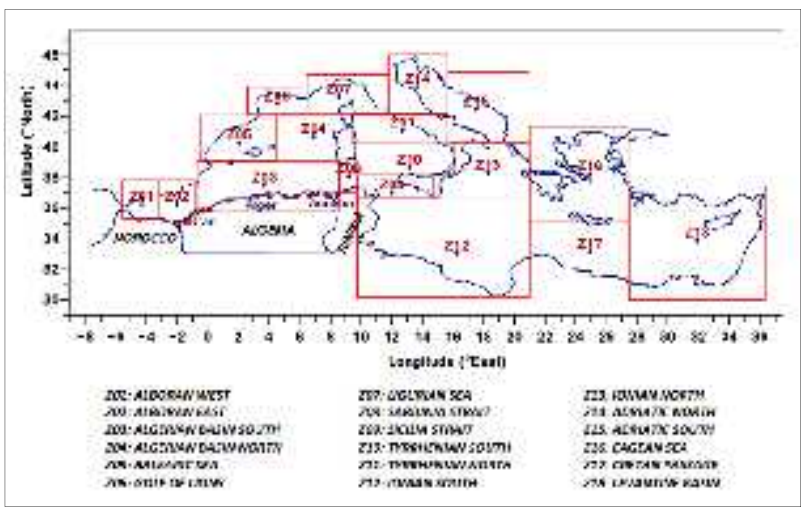

Figure 1. Study area, defined by a grid of 18 spatial points (each point represents a subregion of the Mediterranean Sea surface).

For spatial interpolation, we used linear regressions between a variable in a given zone and the same variable located in adjacent zones to fill in missing values. Only regressions with a high correlation coefficient $(r \geq 0.9)$ were applied in this process. For temporal interpolation, we used the binned and spatially interpolated database to construct 3- and 5-month moving averages. When the one-binned datum is missing, the 3 or 5-binned one replaces it.

At this stage, our database is a monthly climatology of each variable over the 18 zones and covering the period from January 1955 to December 1999. We constructed the average SST and SSS monthly climatologies at 18 zones scale to compare with the upper and lower regional limits. We constructed the average annual and their standard deviation fields to characterize spatial variations and detect areas of high variability. The mean seasonal contrast fields (summer-winter) to study seasonal variations. The mean annual cycles on a global scale (whole Mediterranean Sea) and regional (three sub-basins: occidental "WMS", Central "CMS" and Oriental "EMS") in order to analyse typical annual cycle and establish regional differences. The annual anomalies series to describe inter-annual variations. In order to detect trends in fields, we constructed the average for 4 decades (1958-1969, 1970-1979, 1980-1989 and 1990-1999).

\section{RESULTS AND DISCUSSION}

\subsection{Annual variability}

Monthly climatologies spatially averaged over the whole Mediterranean Sea surface show that the monthly temperature changes heavily in the range of 13 to $27^{\circ} \mathrm{C}$ and increases from north to south and from west to east. While monthly salinity changes more softly with values between 36 and 39 and increases eastwards, except for of Adriatic Sea surface.

Mean annual values of SST and SSS averaged spatially for the eighteen zones and corresponding limits are illustrated in figure 2. It shows that the mean surface temperature of Mediterranean waters ranges from $18^{\circ} \mathrm{C}(\mathrm{Z} 01$ : Western Alboran in the western basin) to over $22.1{ }^{\circ} \mathrm{C}$ (Z18: Levantine Basin in eastern basin). The warmest area is the Levantine Basin, with $22.1^{\circ} \mathrm{C}$. The coolest areas are the Gulf of Lions, the Ligurian Sea and northern Adriatic Sea, with a mean SST of $17.5^{\circ} \mathrm{C}$ (Fig. 2a).

The surface salinity of the Mediterranean Sea softly increases from Gibraltar to Ligurian Sea (from about 37.4 in the western Alboran to 38.5 in Ligurian Sea) with a decline in the Gulf of Lions (about 37.2). From Sardinia Strait to northern Ionian Sea, salinity shows a relative stability around 38.3. It strongly decreases in the Adriatic Sea (about 36.8) and then rises to 39 and upwards in the eastern basin (Fig. 2b). Furthermore, figure 2 shows that these fields vary reasonably between the superior and inferior regional limits.

Figure 3 shows the SST and SSS annual cycles for Mediterranean Sea and these three sub-basins (WMS, CMS and EMS). Annual cycles of temperature showed a clear seasonal cycle at all spatial scales, from minimum values in the range of 13.8-16.4 ${ }^{\circ} \mathrm{C}$ during February to the maximum values $22.8-25.6$ ${ }^{\circ} \mathrm{C}$ during August. The WMS and EMS are in the same magnitude order, from December to April. However, difference grows from April to reach its maximum (about $2.5{ }^{\circ} \mathrm{C}$ ) in August.

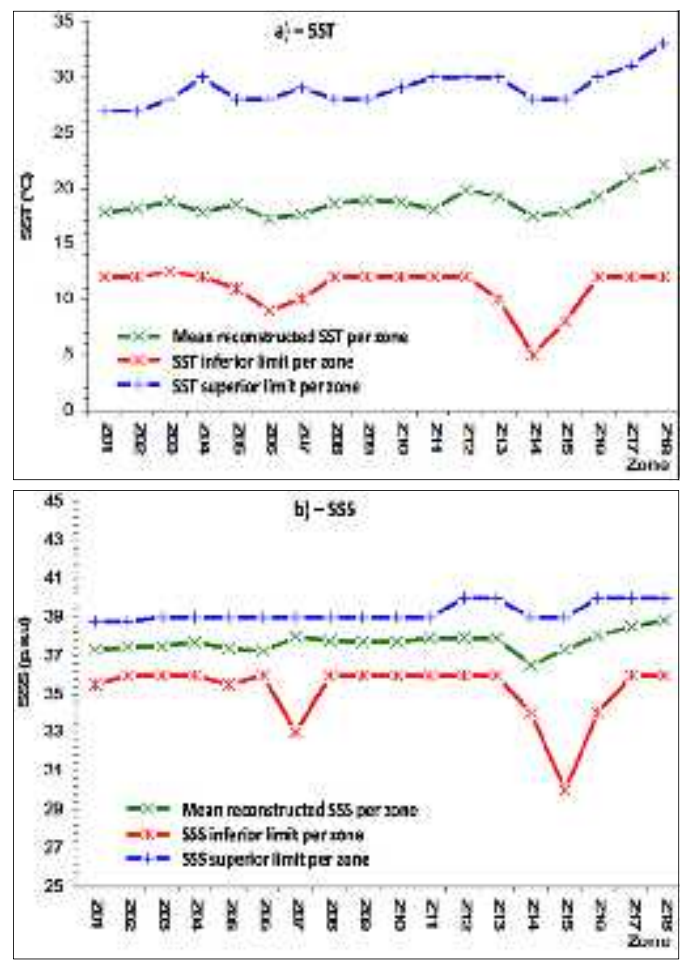

Figure 2. Mean annual SST (a) and SSS (b) at eighteen zones and corresponding limits.

Annual cycles of salinity show a minimum between two peaks values, with salinities are subject to almost linear 
increase/decrease between the periods of these extreme values. The two salinity peaks values observed in November and February, while in the WMS basin observed in August and February. The minimum salinity values are observed in June, except that the EMS exhibits this minimum in April. The lowest salinities generally confined at 37.1-37.4 interval and the highest ones confined at 37.6-37.9 interval, except that the EMS exhibits higher salinities (about 1). The EMS is generally more saline than the WMS, by about 1 (Fig. 3b). The surface salinity increase is in phase with the temperature decrease during February.
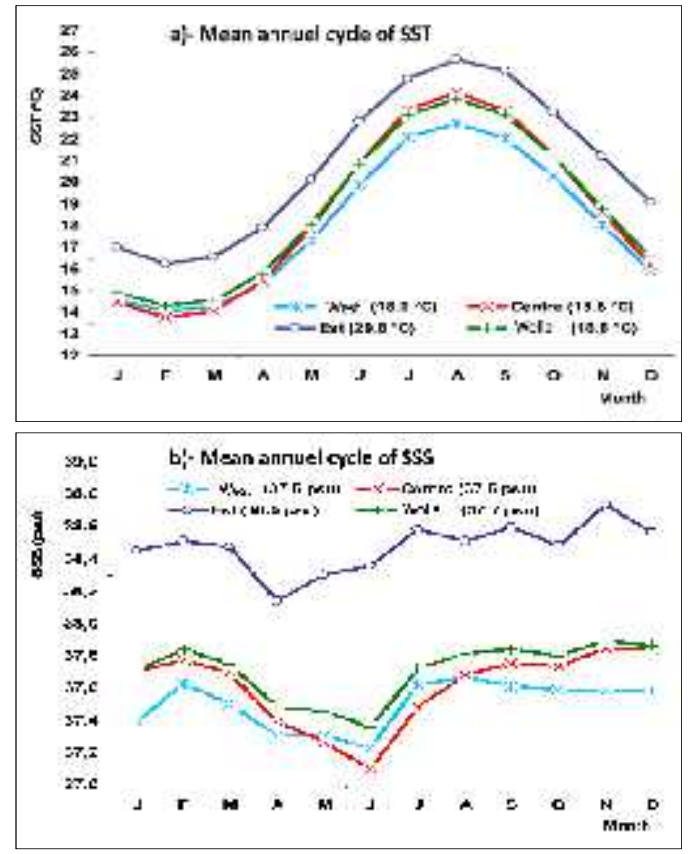

Figure 3. Mean annual cycle of SST (a) and SSS (b) over whole Mediterranean Sea and these three basins, for 1955-1999 period.

The mean seasonal thermal contrast field at Mediterranean surface (Fig. 4a) shows that it undergoes higher summer (JuneAugust) temperatures than winter (December-February). The lowest seasonal gap is located in western Alboran Sea and the Gulf of Lions while the strongest difference is located in the Adriatic notably its northern part. The mean seasonal differences field in salinity (Fig. 4b) shows that the surface waters of the northern boundaries of the Mediterranean are less salty in summer compared to winter, notably in the northern Adriatic.

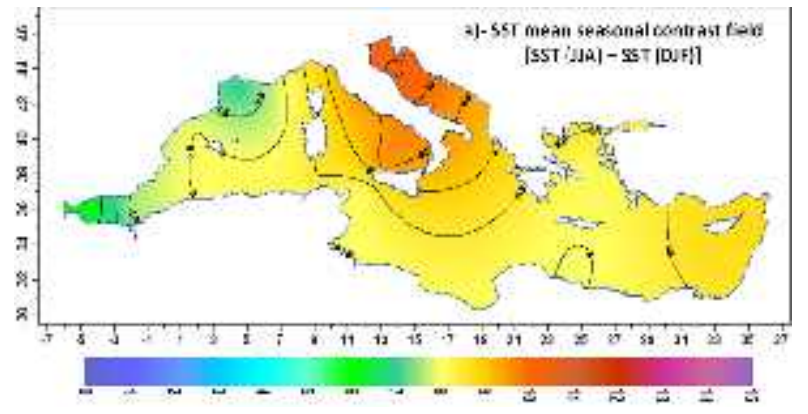

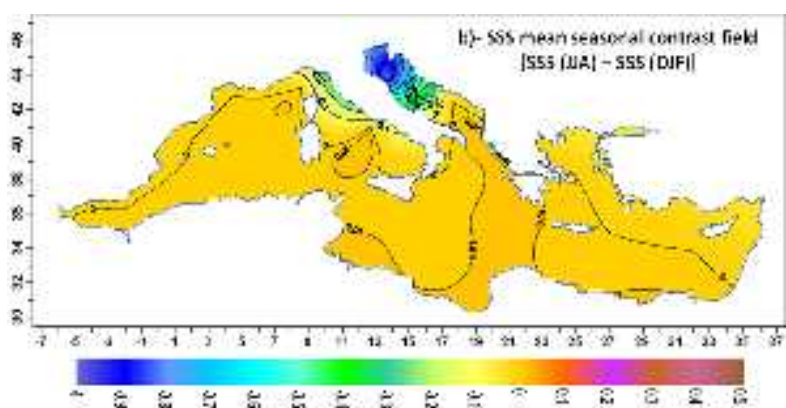

Figure 4. Spatial distribution of temperatures (a) and salinities (b) seasonal contrasts in Mediterranean Sea surface, averaged over 1955-1999 period.

\subsection{Spatial variability}

Figure 5 depicts the spatial variability of surface temperature at Mediterranean Sea based on the mean annual field and its field of average standard deviations. It shows that the north-south temperature gradient $\left(3{ }^{\circ} \mathrm{C}\right)$ is weaker than the west-east gradient $\left(4{ }^{\circ} \mathrm{C}\right)$. The highest SST variability observed in the Gulf of Lions, south of the Aegean Sea. These areas own also the coldest surface water. By cons, the warmer surface waters are in the southeast Levantine Basin. The minimum variability observed in the Alboran Sea and in the central part of the basin, particularly the Sicilia strait and the southern Tyrrhenian Sea.

The WMS surface shows an average temperature of $18{ }^{\circ} \mathrm{C}$. The north-south thermal gradient is slightly stronger than west-east gradient. The coldest water surfaces are located in the northwest (minimum of $17.3{ }^{\circ} \mathrm{C}$ in the Gulf of Lions) and warmer waters are in the southern Algeria basin with a maximum of $18.8^{\circ} \mathrm{C}$. Areas with strong variability and lower temperatures occupy the northwest, whereas the most stable areas and warmer occupy the southern part of this basin. The CMS surface shows an average temperature of $18.9{ }^{\circ} \mathrm{C}$, except that the Adriatic Sea surface exhibits an average temperature of $17.7^{\circ} \mathrm{C}$. The northsouth thermal gradient is stronger than the west-east gradient. Surface temperatures decrease southeastern $\left(20.5^{\circ} \mathrm{C}\right.$ in the Gulf of Syrte) to the northwesterly $\left(17.5^{\circ} \mathrm{C}\right.$ in the north Adriatic). The SST field is relatively stable. Areas with strong variability and lower temperatures occupy the northern Adriatic. The southern Ionian Sea records the strongest surface temperatures. The EMS surface shows an average temperature of over $20{ }^{\circ} \mathrm{C}$ and can reaches $22.2{ }^{\circ} \mathrm{C}$ in the extreme southeast, except that the Aegean Sea surface shows an average temperature varies between 19 and $20{ }^{\circ} \mathrm{C}$. Three sectors are distinguished: the first is the Aegean Sea that shows a clear positive southward gradient. The second is the Crete passage and area located between Crete and Cyprus that shows an increase of SST from west to east. The third one is the southern Cyprus that confines the highest temperatures of whole Mediterranean Sea. To north of Crete, the strong and low variability varies in the same sense. The highest spatial thermal variability and the lowest temperatures occupy the surface of the southern Aegean Sea. 

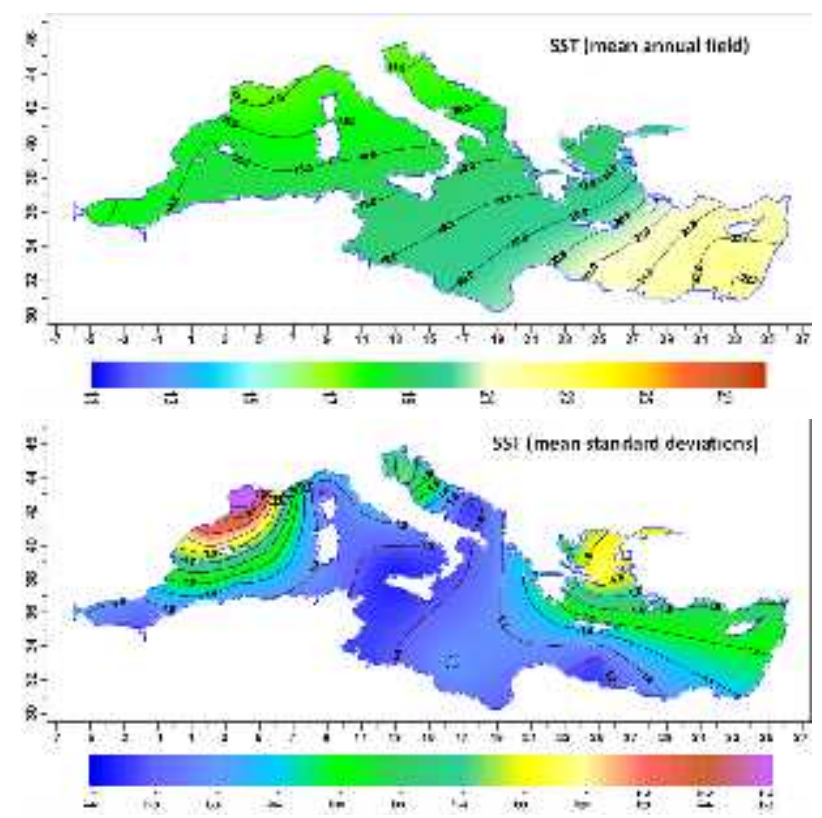

Figure 5. Spatial distribution of temperatures and its mean standard deviations in Mediterranean Sea surface, averaged over 1955-1999 period.

Concerning the salinity, Figure 6 shows that the continuous increase from Alboran Sea (37.2) to the southeast of Levantine basin (38.9) is the more remarkable characteristic, except that the northern Adriatic Sea exhibits an averaged salinity of 36.5. The north-south gradient $(0.3)$ is weaker than the west-east gradient (1.7). The relative increase shaped of an anticyclonic cell (38) covers the southwestern Ligurian Sea and the northwest Tyrrhenian Sea. The less salty waters occupy the north Adriatic surface, with a net cyclonic cell (36.5). The southern Aegean Sea surface maintains a salinity level exceeding the 38 , with a configuration relatively similar to that of SST.

The less salty WMS surface waters are located in western Alboran Sea and in the Gulf of Lions. This latter area also exhibits the strongest variability. The most salty surface waters and less variable occupy the southwest of Ligurian Sea. In this basin, the north-south gradient is weaker than the west east one. In CMS surface, the north-south salt gradient is stronger than the west-east one. Saltiest surface waters occupy the Gulf of Syrte. By cons, the less salty waters are located in the northern Adriatic. The northern Adriatic holds also strongest variability. The saltiest EMS surface waters and most stable are in the southern Levantine basin. While, surface waters less salty and strongest variables are located in the southern Aegean Sea, with a maximum of 1.7. The north-south gradient is weaker than the west-east one, exception for the northern Crete.

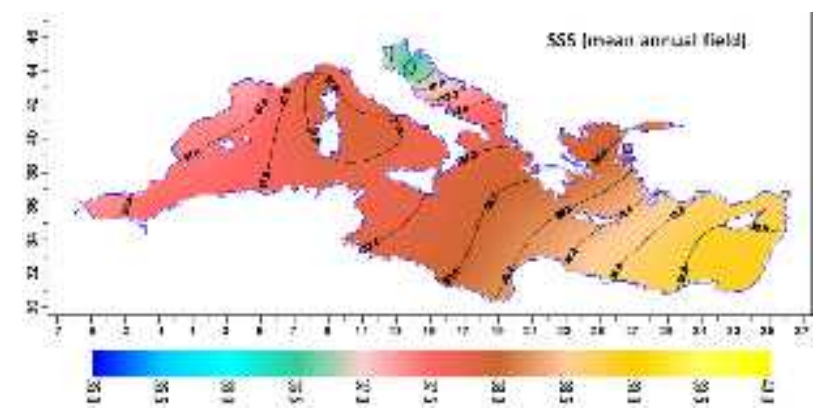

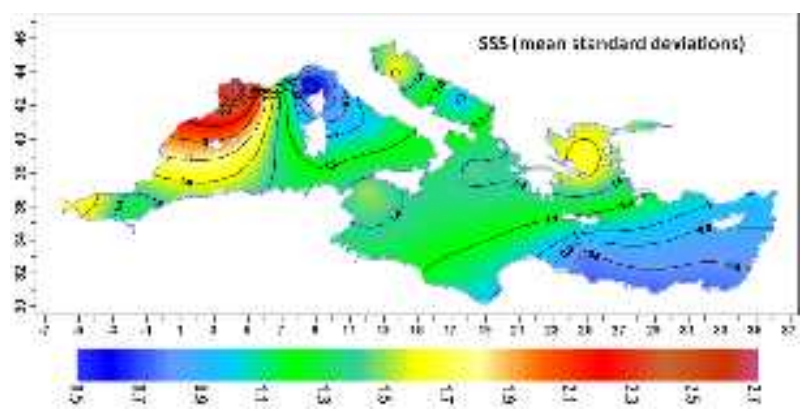

Figure 6. Spatial distribution of salinities and its mean standard deviations in Mediterranean Sea surface, averaged over 19551999 period.

\subsection{Inter-annual/decadal variability}

The annual SST anomalies chronology (Fig. 7a) shows that the largest positive peak of inter-annual SST variability is encountered in 1994, the largest negative peak in 1992. Whereas those related to salinity are observed in 1983 for the largest positive and in 1997 for the largest negative peak (Fig. $7 b)$.

The solid line (Fig. 7a) represents the 5-year running mean, which highlights trends. It indicates a general cooling trend over 1963-1971 period and a general warming trend over 1972-1999 period. A more thorough examination of the time series reveals a very small SST cooling trend in the early nineties (1992-1993) and then a strong warming trend throughout the rest of the record. Related to salinity (Fig. 7b), it shows a general rising trend in salinity over the whole 1963-1985 period then a strong decreasing trend throughout the rest of the record. The rising trend period is disconnected by a decreasing trend during the 1974-1979 period.

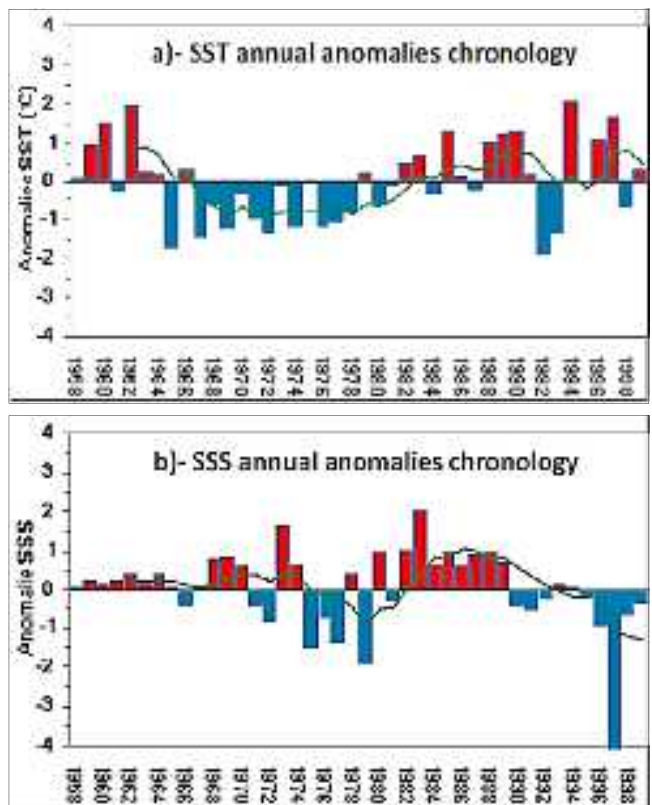

Figure 7. Annual anomalies chronology of SST (a) and SSS (b) in whole Mediterranean Sea, over the 1958-1999 period. Solid lines represents the 5-year running mean. 
The right panels of figure 8 depicts the decadal SST averages from the 1960s (Fig. 8a) to the 1990s (Fig. 8d). It shows that the Mediterranean Sea surface sustained a cooling in the 1970s and an acceleration of the warming in the 1990s. This is particularly true for Gulf of Lions, the Ligurian Sea, the Adriatic and the Aegean Sea where SST increase is northwards. The average increase in sea surface temperature is about $0.2{ }^{\circ} \mathrm{C} /$ decade, although the higher warming rate in the eastern basin. During 1960s (Fig.8a), the warmest area is the Levantine Basin with SST values between 21.4 and $22.2^{\circ} \mathrm{C}$. The coolest area is the Gulf of Lions with SST values less than $17.4^{\circ} \mathrm{C}$. SST decreases clearly from the south to the north in WMS. While in EMS, it increases from the west to the east, especially in Levantine Basin. The basin-average SST decrease during the 1970s (Fig. $8 \mathrm{~b})$ which is particularly pronounced in the northern parts of WMS, of Adriatic and of Aegean Sea. During 1980s (Fig. 8c), there is a gradual increase of SST but with a higher warming trend in the western basin than in the Levantine basin. During this decade, only the northernmost Adriatic Sea surface remaining with temperature of $17.5^{\circ} \mathrm{C}$. During the 1990s (Fig. $8 \mathrm{~d})$, there is an acceleration of the warming in the western basin and the SST warming rate becomes larger in the eastern than in the western sub-basin. During this decade, temperature is higher than $17{ }^{\circ} \mathrm{C}$ in the entire Mediterranean Sea surface, with the SST increasing northward in the WMS and eastward in the EMS.

The left panels of figure 8 illustrates the decadal salinity averages from the 1960s (Fig. 8e) to the 1990s (Fig. 8h). It indicates that there is a discernible trend of increased salinity corresponds to the cooling periods. Conversely, the decreased salinity is associated with the warming periods; this is particularly true for the western part of WMS, for Adriatic Sea and for Levantine basin during 1990s. During 1970s, surface salinity shows a general increasing trend, except that for the northern Adriatic and the western of Alboran that exhibit a decreasing (Fig. 8f). The inverted situation during 1980s, except that for the northern Adriatic Sea that continued in its decreasing salinity trend (Fig. 8g). During this decade, increasing trend concerns all Mediterranean surfaces located south of 40 degrees. During 1990s (Fig. 8h), surface salinity shows an acceleration of decreasing trend for all Mediterranean surfaces, except for Levantine Basin that exhibits a relatively increasing trend.

\subsection{Discussion}

In the present study, we used 18 identified zones (Fig. 1). This partition does not take into account the biogeochemistry and ecology features of the Mediterranean Sea. More recently, several studies have attempted to partition the basin either using abiotic parameters (Gabrié et al., 2012) or biotic parameters (D'Ortenzio \& D'Alacala, 2009). These studies have confirmed a no stationary picture of the basin dynamic and significant biogeochemical differences between regions that have consequences on the local dynamic.

The various climatologies constructed indicate some main features that deserve to be discussed. Surface thermal field reveals a clear north-to-south and the west-to-east gradients. Salinity field increases eastwards from Gibraltar to eastern basin (Fig. 2). The warmest and saltiest area is Levantine Basin. While, the coolest and less salty areas are the Gulf of Lions and the Ligurian Sea. The principal atmospheric and ocean circulation forcing mainly support those gradients, regional features such as Atlantic Ocean or river run-off influence on the occidental basin. Temperature seasonal cycle is more marked with respect to the salinity seasonal cycle (Fig. 3) which related especially to the solar radiation seasonal cycle. The EMS exhibited higher temperatures $\left(\approx 2{ }^{\circ} \mathrm{C}\right)$ than those at WMS, especially in winter (Fig 3a). The EMS is generally more saline than the WMS $(\approx 1)$ that is related to the climate induced by the intense evaporation from the eastern basin resulting in Levantine Intermediate Water formation. At the surface, three major factors driven salinity dynamics: the input in marginal seas (terrestrial input from the Po and other Italian rivers and from the Dardanelles), the effect of evaporation in the eastern basin and the influx of the low-salinity Atlantic water. The thermohaline basin-wide circulation modulates the intensity and the patterns of the spatial gradients.

The average seasonal thermal contrast field (Fig. 4a) indicates a weaker contrast located in western Alboran Sea and the Gulf of Lions. In the Gulf of Lions, this contrast can be explained by the upwelling phenomenon, most active during the spring that reduces the temperature deviation between summer and winter in this zone. In the Alboran Sea, the low contrast can be explained by the nature of surface waters which originated from the Atlantic and that have a relatively homogeneous temperature throughout the year, by the air flux from the southwest established by the displacement to the south of the Azores anticyclone, during the summer. This flux brings relatively cool air masses from Atlantic that reduce the surface temperature in the Alboran Sea surface, during this season. The strongest seasonal contrast is located in the Adriatic Sea, notably its northern part. It can be explained by the cold winter winds (the Bora, Tramontane) that cool surface waters in these regions. In the rest of Mediterranean surfaces, we can explain this thermal contrast by the displacement of Hadley Cell northwards during summer, by the Sirocco in the southern Mediterranean and by the Etesian in the Aegean Sea. These factors further may warm surface waters in these regions and, therefore, amplify the summer-winter temperature contrast in the Mediterranean.

The average seasonal contrast in salinity (Fig. 4b) indicates that the surface waters of Mediterranean northern boundaries are less salty in summer compared to winter, notably in the northern Adriatic. 

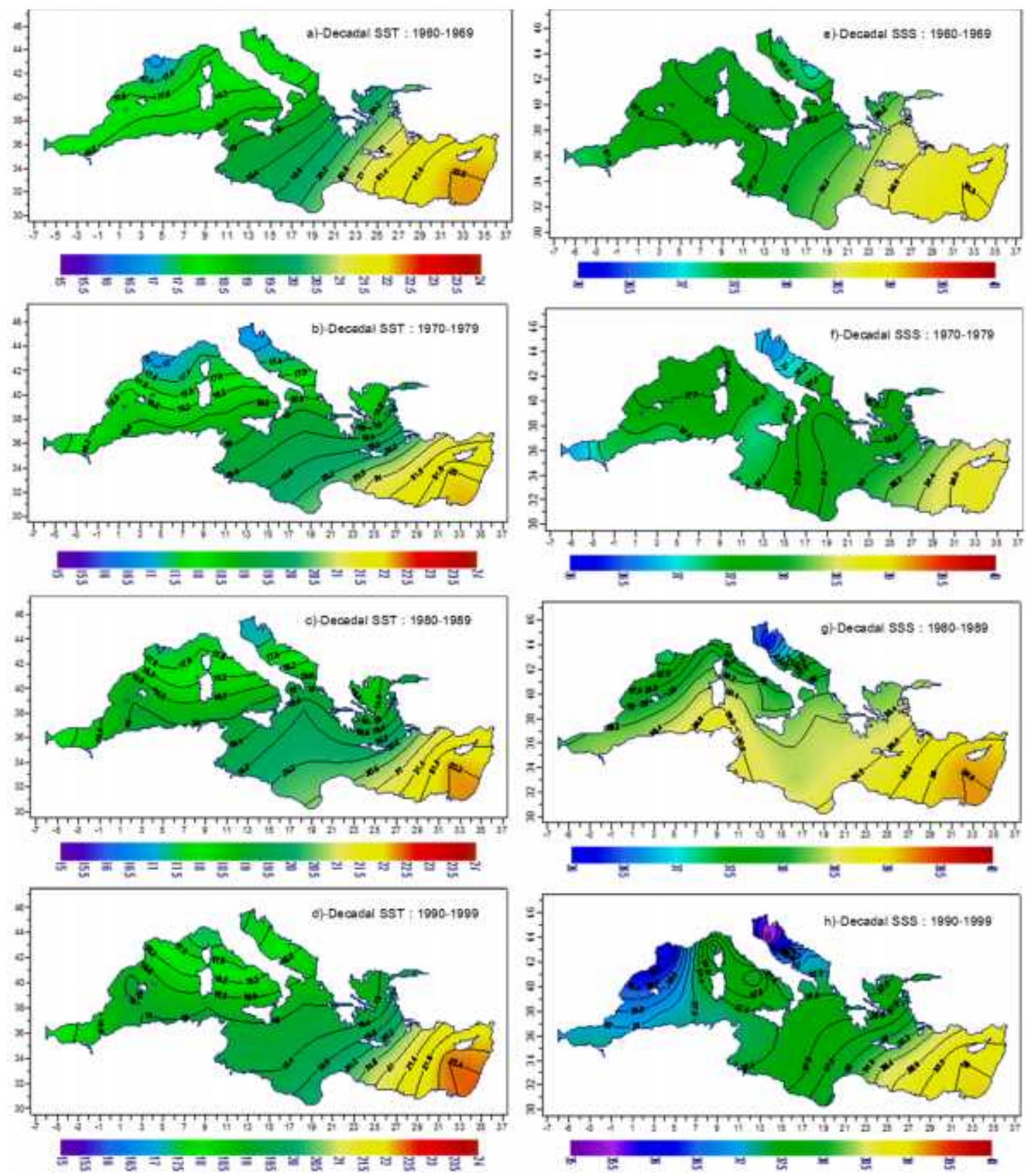

Figure 8. Averaged SST (left panels) and SSS (right panels) in the Mediterranean Sea over the (a - e) 1960s, (b-f) 1970s, (c - g) 1980s, and $(\mathrm{d}-\mathrm{h})$ 1990s. 
In the Adriatic and the northwestern Mediterranean Sea, the surface salinity contrast can be explained by the freshwater inputs from rivers (Rhone, Po) after the late spring merger of the reliefs snow (Pyrenees, Alps, Apennines). In the Aegean Sea, it can be explained by the water exchange between Black Sea and Aegean Sea, also by the evaporation increases in summer. The increase in surface salinity is in phase with the decrease in temperature during February that explains the downwelling of surface waters denser in late winter. Thus, the seasonal differences in salinity and surface temperature clearly reflected the forcing that induces the vertically circulation in Mediterranean Sea. These findings are consistent with observations and modelling studies of the Mediterranean climate variability (Coll et al., 2010; Woodruff et al., 2008; Somot, 2005; Levitus et al., 2005, 2009).

Spatial distribution of both fields reveals a weaker northsouth gradient than the east-west one and the strongest variability is sharper in downwelling areas than anywhere else. The external surface water masses input mainly determines this spatial variability, also the spatial variability of air-sea heat fluxes and the upward vertical transports of intermediate water due to turbulent mixing and/or upwelling processes (Mariotti, 2010). Our results highlight favourable areas for the existence of convective processes in the Mediterranean Sea and the production of dense water masses with low temperature and high salinity characteristics, and are consistent with the existing knowledge and major experiments that led to the discovery of the sub-basin scale circulation and its mesoscale features (Bergamasco \& Malanotte-Rizzoli, 2010).

The observed increasing warming of the Mediterranean Sea surface can be related to the East Atlantic pattern index variability that seems to follow the global warming trend, accelerated after the early 1990s. The SST yearly anomalies can be related to the Atlantic Multidecadal Oscillation (AMO) index yearly mean variability. Our results are consistent with the study of Mariotti and Dell'Aquila (2011) who found a high correlation between AMO and the Mediterranean SST throughout the year over the period 1870-2009. The brief surface cooling period occurred during the early 1990s can be associated with a more prolonged cooling in the Atlantic area west of Gibraltar. After the early 1990s, the SST warming rate becomes larger in the eastern than in the western basin. This behaviour can be explained by the local ocean processes such as the heat horizontal advection (from the western basin) and/or vertical mixing which probably control the accelerated surface warming in the eastern basin.

The enhanced variability shift observed in the Mediterranean SST in the early 1990s may be explained partly by the North Atlantic Oscillation (NAO) index variations. The high positive NAO phase is associated with warmer conditions over the western sub-basin and cooler conditions over the eastern sub-basin, while the contrary occurs during negative NAO phases. Atmospheric conditions seem to control the net air-sea heat flux and SST variations. In particular, the large SST increase in the western basin during the late 1980s seems to follow closely both NAO index and the net airsea heat flux increase. In the early 1990s, a large atmospheric variability shift occurred as evidenced by the abrupt decrease of both. This NAO variability probably contributed to the change in the SST spatiotemporal variability pattern and it is associated with the change in the direction of the SST spatial increasing tendency in the Mediterranean Sea (i.e. from the westward to the eastward direction).

The observed increase, since 1980s, in surface temperature is generally higher in northern than in southern Mediterranean Sea, with a rapid warming since the mid-1990s. Surface cooling along with the combined salt content increase of the Eastern Mediterranean induced by increased net evaporation during this period may gradually decrease stratification in the Aegean Sea resulting in larger deep-water formation rates favouring the Eastern Mediterranean Transient (EMT). Those findings are consistent with recent observations (Russo et al., 2002) and the Atmosphere-Ocean Regional Climate Models (Somot et al., 2008; Skliris et al., 2007). The strong negative anomaly salinity decrease observed during 1996-1997 period, can probably reduce the Aegean Dense Water Formation (DWF) efficiency and led to a long-term decay phase for the EMT. In general, the temperature has fluctuated from cold conditions through the 1960s and 1970s to recent warming that commenced in the 1980s. These events are thought to be predominantly a consequence of climate change (Solomon et al., 2007; Hoegh-Guldberg \& Bruno, 2010). The long-term surface warming may have an impact on the future thermohaline circulation of the Mediterranean Sea. A significant increase of SST may diminish the dense water formation rates in the various deep/intermediate water formation sites of the basin and thus may slow down the thermohaline circulation. Changes in the temperature and salinity of the outflowing Mediterranean water through the Gibraltar strait may influence the general circulation in the North Atlantic, which is a major site of deep-water formation controlling the global thermohaline circulation.

\section{CONCLUSION}

Thanks to MEDATLAS 2002 database release, which we used to construct the various climatological fields of temperature and salinity at Mediterranean Sea surface. These climatology fields served as tools for spatiotemporal. The climatological characteristics can serve as "benchmark" for carrying out further analysis of the changes in the oceanographic properties that may have occurred during the last years in the Mediterranean Sea. Climatologies thus realized can contribute to improve ocean-atmosphere interactions at local scales, understanding the mechanisms causing interannual downwelling variations in the Mediterranean and improving the constraints for the ocean-atmosphere coupled models.

The Mediterranean Sea surface hydrology characteristics (temperature, salinity) show a high interannual variability as well as long-term trends over the last decades. During 1980-1990, there is a significant SST rise in the western basin following a large warming of the inflowing surface Atlantic waters and a long-term increase of the NAO index, whereas SST slowly increased in the eastern basin. After a brief cooling 
period in the early 1990 s for both sub-basins and a change from a high positive to a low NAO phase, the Mediterranean mean warming rate accelerated while its spatial increasing tendency changed from the westward to the eastward direction. The increasing trend in temperature encountered in the MEDAR/MEDATLAS 2002 data from the 1960s to the 1990 s has to be confirmed by other datasets and/or if more recent data become available (e.g. 2000s and 2010s). If this trend persisted, it would most likely have had an impact on the future thermohaline circulation of the Mediterranean Sea and a significant effect on the Mediterranean Sea marine ecosystems, as well as on the marine biogeochemical cycles.

The study identified a clear effect of sea surface warming on marine ecosystems favouring and accelerating the settlement of new alien species at an unexpectedly rapid rate. The rate of entrance of the new invaders is greater than the temperature rate itself, presenting an important warning for the future of Mediterranean Sea biodiversity. This might have profound consequences for marine biodiversity, restructuring the whole ecosystem with potential consequences for ecosystem functioning and services. From the preceding analysis, a number of research needs can be identified. These include the identification and further analysis of historical data to describe past Mediterranean climate and ecosystem development, and a better understanding of biogeochemical fluxes, food web dynamics and ecosystem functioning, including feedback mechanisms, under current predictions of climate change.

\section{REFERENCES}

Barnier B., Brodeau L. and T. Penduff, 2006. Ocean surface forcing and surface fields. Mercator Ocean Quaterly Newsletter, pp. 4-7.

Beniston Martin, 2004. The Climate System, In Climatic Change and Its Impacts. Advances in Global Change Research, 19, pp. 27-52.

Bergamasco A. and P. Malanotte-Rizzoli, 2010. The circulation of the Mediterranean Sea: a historical review of experimental investigations. Advances in Oceanography and Limnology, 1(1), pp. 11-28.

Béthoux J. P. Gentili B, Morin P., Nicolas E., Pierre C. and D. Ruiz-Pino, 1999. The Mediterranean Sea: a miniature ocean for climatic and environmental studies and a key for the climatic functioning of the North Atlantic. Progress in Oceanography, 44, pp. 131-146.

Bryden H.L., Candela J., T. H. Kinder, 1994. Exchange through the strait of Gibraltar. Progress in Oceanography, 33, pp. 20-248.

Castellari S, Pinardi N. and K. Leaman, 1998. A model study of air-sea interactions in the Mediterranean Sea. Journal of Marine Systems, (18), pp. 89-114.

CIESM, 2002. Tracking long-term hydrological change in the Mediterranean Sea, CIESM Workshop Series, 16, $134 \mathrm{pp}$

Coll M., Piroddi C. and al., 2010. The biodiversity of the Mediterranean Sea: estimates, patterns and threats. PLOS ONE, 5 (8), e11842. doi:10.1371/journal.pone.0011842
D’Ortenzio F. and M. Ribera D’Alcalã, 2009. On the trophic regimes of the Mediterranean Sea: a satellite analysis. Biogeosciences, 6, pp. 139-148.

Fichaut M, Garcia M. J., Giorgetti A., Iona A., Kushmaro A. et al., 2003. MEDAR/MEDATLAS 2002: a Mediterranean and Black Sea database for the operational Oceanography. Proceedings of the third International Conference on Euro-GOOS, December 2002, Athens, Greece. Oceanography Series 69, pp. 645648.

Gabrié C., Lagabrielle E., Bissery C., Crochelet E., Meola B., Webster C., Claudet J., Chassanite A., Marinesque S., Robert P., Goutx M. and C. Quod, 2012. Statut des Aires Marines Protégées en mer Méditerranée. Med PAN Collection, 260 pp.

Gill A.E., 1982. Atmosphere-Ocean Dynamics. Int. Geophys. Ser., Academic Press, 30, New York and London, $662 \mathrm{pp}$

Hewitt C.D. and D.J. Griggs, 2004. Ensembles Based Predictions of Climate Changes and their Impacts. EOS, (85), 566 pp.

Hoegh-Guldberg O. and J.F. Bruno, 2010. The impact of climate change on the world's marine ecosystems. Science, 328, pp. 1523-1528.

Intergovernmental Panel on Climate Change (IPCC), 2007. Impacts, Adaptation and Vulnerability. Cambridge Univ. Press, Cambridge, UK.

Lebeaupin C., Ducrocq V. and H. Giordani, 2006. Sensitivity of Mediterranean torrential rain events to the Sea Surface Temperature based on high resolution numerical forecasts. Journal of Geophysical Research, 111 (D12), 12110 10.1029/2005JD006541

Lejeusne C., P. Chevaldonné, C. Pergent-Martini, C.F. Boudouresque and T. Pérez, 2010. Climate change effects on a miniature ocean: the highly diverse, highly impacted Mediterranean Sea. Trends Ecol. Evol., 25, pp. 250-260.

Levitus S., Antonov J. I. and T. P. Boyer, 2005. Warming of the World Ocean, 1955-2003. Geophys. Res. Lett., 32, L02604, doi: 10.1029/2004GL021592

Levitus S., Antonov J. I., Boyer T. P., Locarnini R. A., Garcia H. E. and A.V. Mishonov, 2009. Global ocean heat content 1955-2008 in light of recently revealed instrumentation problems. Geophys. Res. Lett., 36, L07608, doi:10.1029/2008GL037155

Li L., 2006. Atmospheric GCM response to an idealized anomaly of the Mediterranean Sea surface temperature. Clim. Dyn., Doi: 10.1007/s00382-006-0152-6

Lionello P., 2012. The climate of the Mediterranean region: From the past to the future. Elsevier Edit, 584 pp

Mariotti A. and A. Dell'Aquila, 2011. Decadal climate variability in the Mediterranean region: roles of largescale forcing and regional processes. Clim Dyn., doi: 10.1007/s00382-011-1056-7

Mariotti A., 2010. Recent changes in the Mediterranean water cycle: a pathway toward long-term regional hydroclimatic change. Journal of Climate, 23, pp. 15131525.

MEDAR Group 2002. MED-ATLAS 2002 database: Mediterranean and Black Sea database of temperature salinity and biochemical parameters. Climatological 
Atlas. IFREMER.

Millot C. and F. Briand, 2002. Executive summary in Tracking Long-Term Hydrological Change in the Mediterranean Sea. CIESM Workshop Series, 16, pp. 7 14.

Millot C. and I. Taupier-Letage, 2005. Circulation in the Mediterranean Sea. The Handbook of Environmental Chemistry, K, doi: 10.1007/b107143, pp. 29-66.

Millot C., Candela J, Fuda J. L. and Y. Tber, 2006. Large warming and salinification of the Mediterranean outflow due to changes in its composition. Deep-Sea Res., 53 (4), pp. 656-666.

Pickard G. L. and W.J. Emery, 1964. Descriptive physical oceanography. Butterworth Heinemann, Oxford.

Potter R. and S. Lozier, 2004. On the warming and salinification of the Mediterranean Outflow waters in the North Atlantic. Geophys. Res. Lett., 31, L01202, doi : 10.1029/2003GL018161

Pusceddu A, Mea M, Gambi M, Bianchelli S, Canals M, Sanchez-Vidal A et al., 2010. Ecosystem effects of dense water formation on deep Mediterranean Sea ecosystems: an overview. Advances in Oceanography and Limnology, 6(1), pp. 67-83.

Romanou A., Tselioudis G., Zerefos C.S., Clayson C., Curry J.A. and A. Andersson, 2010. Evaporationprecipitation variability over the Mediterranean and the Black Seas from satellite and reanalysis estimates. Journal of Climate, 23, pp. 5268-5287.

Russo A., Rabitti S. and M. Bastianini, 2002. Decadal climatic anomalies in the Northern Adriatic Sea inferred from a new oceanographic data set. PSZNI Mar. Ecol., 23, pp. 340-351

Sanchez Gomez E, Somot S. and A. Mariotti, 2009. Future changes in the Mediterranean water budget projected by an ensemble of Regional Climate Models. Geophys. Res. Lett.

Sanchez-Gomez E, Somot S and M. Déqué, 2008. Ability of an ensemble of regional climate models to reproduce weather regimes over Europe-Atlantic during the period 1961-2000. Clim. Dyn., 10, 1007/s00382008-0502-7

Simmons A. J. and L. Bengtsson, 1984. Atmospheric general circulation models, their design and use for climate studies. In The Global Climate, Cambridge University Press, $211 \mathrm{pp}$

Skliris N., Sofianos S. and A. Lascaratos, 2007. Hydrological changes in the Mediterranean Sea in relation to changes in the freshwater budget: a numerical modelling study. J. Mar. Syst., 65, pp. 400-416.

Solomon S., Qin D., Chen Z., Marquis M., Averyt K.B., Tignor M. and H.L. Miller, 2007. Contribution of Working Group I to the Fourth Assessment Report of the Intergovernmental Panel on Climate Change. Cambridge University Press, 996 pp.

Somot S., Sevault F., Déqué M. and M. Crépon, 2008. 21st century climate change scenario for the Mediterranean using a coupled atmosphere-ocean regional climate model. Glob. Planet. Change, 63, pp. 112-126.

Somot S., 2005. Modélisation climatique du bassin méditerranéen : Variabilité et scénarios de changement climatique. Ph.D. thesis. Spec. Phys. du Clim., Univ. Toulouse III Paul Sabatier, Toulouse, France, 333 pp.

Timplis M., Zervakis V., Josey S., Peneva E.L., Struglia M.V., Stanev E., Teocharis A., Lionello P., Malanotte Rizzoli P., Artale V, Tragou E. and T. Oguz, 2005. Changes in the Oceanography of the Mediterranean Sea and their Link to Climate Variability. Ed. Elsevier, pp. 226-281

Timplis M., and H.L. Bryden, 2000. Estimation of the transport through the strait of Gibraltar. Deep Sea Research, 47 (1), pp. 2219-2242.

Woodruff S.D., Diaz H.F., Kent E.C., Reynolds R.W. and S.J. Worley, 2008. The evolving SST record from ICOADS, in Climate Variability and Extremes during the Past 100 Years. Advances in Global Change Research, 33, pp. 65-83.

Copyright (C) International Journal of Engineering and Geosciences (IJEG). All rights reserved, including the making of copies unless permission is obtained from the copyright proprietors 